\title{
Three-Phased Risk-Management Benchmark for Internationalization of Small and Medium-Sized Construction Companies
}

\author{
Wooyong Jung, , Seung Heon Han ${ }^{\mathrm{b}}$, Chanyoung Park ${ }^{\mathrm{c}}$, Changjun Lee ${ }^{\mathrm{d}}$, and Seungwon Baek
}

${ }^{a}$ Member, Dept. of Nuclear Power Plant Engineering, KEPCO International Nuclear Graduate School, Ulsan 45014, Korea

${ }^{b}$ Member, Dept. of Civil and Environmental Engineering, Yonsei University, Seoul 03722, Korea

'Intelligent Construction Automation Center, Kyungpook National University, Daegu 41566, Korea

${ }^{d}$ Dept. of Civil and Environmental Engineering, Yonsei University, Seoul 03722, Korea

\section{ARTICLE HISTORY}

Received 9 September 2021

Accepted 24 October 2021

Published Online 31 December 2021

\section{KEYWORDS}

Benchmark

Small and medium-sized

construction company

Risk

Capability

Subcontract

Contract

\begin{abstract}
Small and medium-sized construction companies (SMCCs) typically lack the international experience of their large counterparts. International construction projects often are more uncertain than domestic projects, which can pique SMCCs' interest or necessity for external benchmarks of best practices. This study aims to provide a three-phased risk-management benchmark framework for the internationalization of SMCCs. The first-phase benchmarking evaluates how well companies prepare to undertake business abroad and what capabilities they should improve upon based on comparative data from 41 SMCCs. The second-phase benchmarking provides risk information from 49 international subcontract projects that must be managed for SMCCs. In the last phase, the benchmark delivers subcontractor risk-response strategies through the analysis of 134 international-contractual cases. Additionally, the three illustrative cases show that the benchmark framework and metrics are quite helpful for decision-makers and SMCC practitioners in evaluating and responding to their international construction project risks.
\end{abstract}

\section{Introduction}

Considerable benchmark research efforts have contributed to the body of knowledge of project performance (Garnett and Pickrell, 2000; Luu et al., 2008; Yeung et al., 2013). Project performance benchmark subjects have gradually expanded from traditional quality measurement to productivity, safety, scheduling, environment, life-cycle management, and building information modeling (ElMashaleh et al., 2010; Ahn et al., 2013; Iyer and Banerjee, 2016; Yun et al., 2016; Liu et al., 2017; Choi et al., 2020; Elsayegh and El-adaway, 2021; An et al., 2021). These benchmarks are both needed and required when users lack sufficient or proper internal references for evaluating project management performance (Barber, 2004). For example, integrated project delivery (IPD) has yet to be applied compared with such general project delivery as designbuild or design-bid-build, so, many project owners and contractors cannot easily guarantee IPD's effectiveness and efficiency for the purpose of performance improvement. Thus, Hanna (2016) provides a benchmark for IPD performance metrics, which explains when and how IPD delivery is superior to non-IPD delivery using benchmark information. Similarly, most SMCCs that are willing to engage in international construction projects have limited experience and access to best-practice data compared with large contractors (Oviedo-Haito et al., 2014). Such benchmark information as internationalization capability, country risk, localization, and subcontracting practices, therefore, can be useful for SMCCs in preparing for, selecting, and executing international construction projects.

Fundamentally, the international construction market encounters more uncertainties than the domestic market (Ofori, 2007; Deng et al., 2014; Viswanathan and Jha, 2020). Thus, many companies, especially SMCCs, have preferred to expand their domestic market share for stable revenue growth and profit rather than exploring abroad. However, as the domestic market growth in many developed countries is slowing and openness to international markets is expanding, SMCCs have gradually started doing business abroad (Jung et al., 2010; Lee et al., 2018). For example, Korean SMCCs have been by and large expanding their overseas

CORRESPONDENCE Seung Heon Han $\varangle$ shh6018@yonsei.ac.kr $\equiv$ Dept. of Civil and Environmental Engineering, Yonsei University, Seoul 03722, Korea

(c) 2022 Korean Society of Civil Engineers 


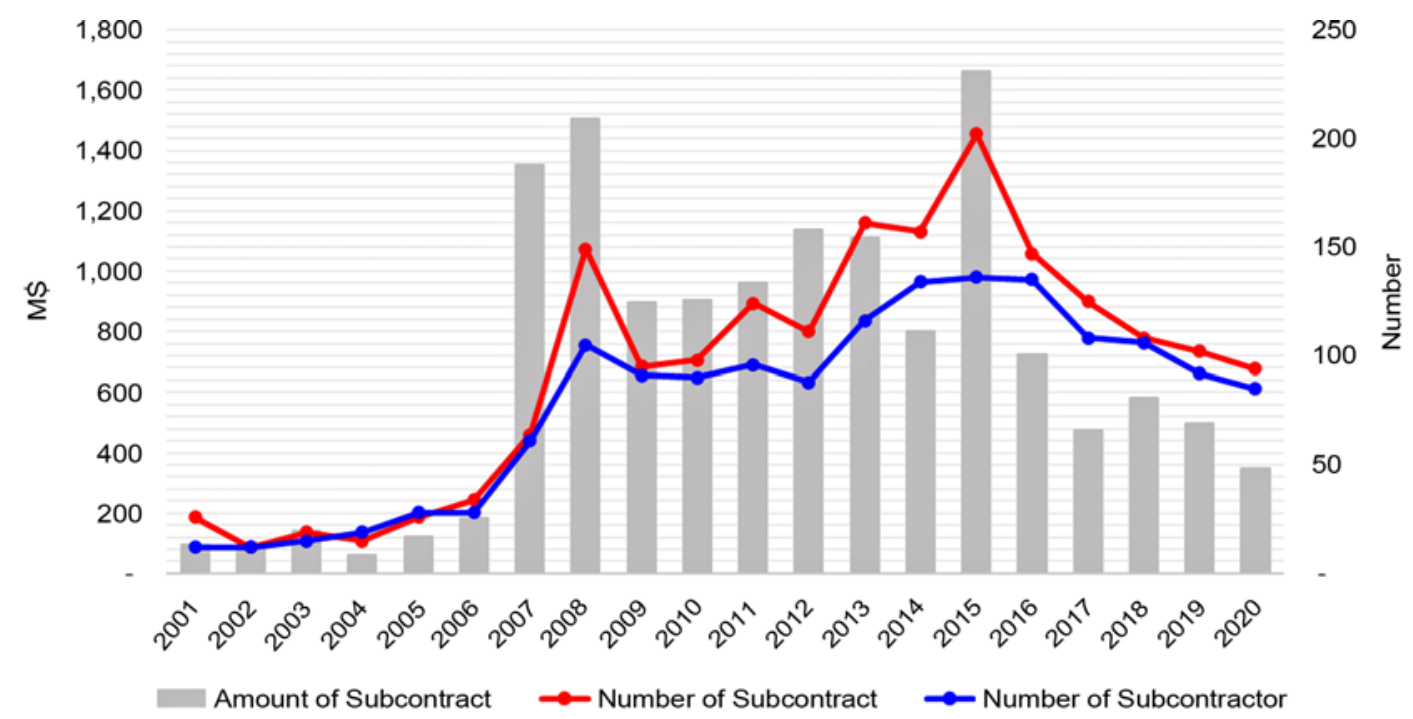

Fig. 1. Subcontract Numbers and Award Amounts of Korean International SMCC

businesses except for recent years, as shown in Fig. 1 (ICAK, 2021). Even though the drop in oil prices and Covid 19 have reduced international bid winning, the number of Korean international SMCC projects in 2020 is still seven times higher than 20 years ago. Spanish and Australian subcontractors have also been expanding their business internationalization over the past several decades (London, 2010; Khan, 2017).

SMCCs have suffered various difficulties in executing projects in their efforts at internationalization, including a lack of market information, scarcity of skilled labor, culture differences, contract routine issues, and financial constraints (Stewart et al., 2003; Ribeiro and Fernandes, 2010). Thus, SMCCs have yielded a low level of average profit as compared with large construction contractors working on international projects (Jung et al., 2010). Despite these facts, there are limited risk-management studies for international SMCCs to assess their relevant project risks (Park et al., 2011; Oviedo-Haito et al., 2014; Lee et al., 2018).

This study aims to provide SMCCs with a phase-based riskmanagement benchmark framework and references for better performance on international subcontract projects. For the first phase, the researchers investigated 24 capability indicators from 41 international SMCCs to create internationalization capability benchmark references. Subcontractors inexperienced with international projects can use these benchmark references to judge their relative competence in the entry of international projects and evaluate which capability factors should be improved before going abroad. The second phase delivers project risk levels compared with other international subcontract projects, examining 77 project risk indicators from 49 international subcontract projects. Subcontractors less experienced with international work can use the comparative assessment of the project's risk before deciding on bid participation. The last phase provides subcontractors with actual practices corresponding to each risk indicator from the second phase. This phase collects the 134 contractual cases involved in international SMCCs and suggests apposite cases for controlling key contractual risk factors. Thus, this three-phased benchmark framework supports SMCC's decision-makers and project managers in evaluating international business capabilities and project risks and responding with proactive contract management.

\section{Research Background}

\subsection{Risk Management Difficulties of International SMCCS}

An international construction project presents considerable risk compared to domestic construction projects, which can induce cost overruns and poor profit (Baloi and Price, 2003; Fidan et al., 2011; Chang et al., 2019). Thus, many researchers have studied risk factors or critical success factors to increase international project performance (Hastak and Shaked, 2000) and have derived international project risk at the country, market, and project levels. This risk breakdown structure is well organized but fails to consider different viewpoints between contractors and subcontractors. Han et al. (2007) suggested 64 risk factors that resulted in poor profit from 126 overseas construction projects. They investigated 20 large international contractors and indicated the gap in risk score between successful and failed international projects. Jha and Devaya (2008) derived 14 key risk factors in international projects conducted by top Indian construction companies and analyzed the influences on and dependence between each risk factor. Bu-Qammaz et al. (2009) also suggested 28 risk factors in a hierarchical risk breakdown structure from international contractors. Liu et al. (2018) considered 60 international construction risk factors by reviewing a wide scope of literature, evaluating the occurrence and magnitude of each risk factor through an investigation of 87 contractors and 17 subcontractors. Lastly, Siraj and Fayek (2019) identified a total of 571 risks through reviewing 130 academic articles that studied risk identification and classification in the construction industry, 
further classifying risks into 11 categories and presenting the top 10 common risks of each category. As the research mentioned above shows, international project risks have been studied for large contractors but not for SMCCs, and international projects by SMCCs have a different risk perspective from international projects undertaken by large contractors. First, SMCCs are small organizations with weak financial stability and have not necessarily acquired internationally experienced resources. Financially, they cannot usually afford to invest in the long-term investigations necessary for localization without the guarantee of winning awards. These insufficiencies lead to difficultly in identifying and managing country-oriented project risk, including such local issues as working and contract practices, supply chain structure, regulation, and so on (Jung et al., 2010). Thus, they must check their ability to react to country-oriented risk and their financial resiliency before doing business in a foreign country. Second, subcontract risk is somewhat different from prime-contract risk. Owner-oriented risk, such as design error and site handover delay, is lower for subcontractors than prime contractors, whereas field construction-oriented risk, such as low productivity and material procurement, might be larger for a subcontractor than for a prime contractor. In addition, subcontracting risks can be reduced or multiplied depending on the relationship between the prime contractor and subcontractor and the prime contractor's capability and experience (Oviedo-Haito et al., 2014). Last, SMCCs have fewer internal project references to evaluate the project risk compared with large contractors. Recently, many large contractors have conducted international construction projects, which enables them to accumulate lessons-learned knowledge. They can build their internal benchmark information for selecting bad projects, evaluating risk levels, and managing contract conflicts, which are helpful for managing international project risk (Liu et al., 2018). SMCCs lack internal track records, so they need to acquire external benchmark information to better manage risk.

\subsection{Benchmarking Approach in Risk Management}

There are many areas of risk management, such as risk identification, assessment, and mitigation (Jepson et al., 2020), and many strategies to address them: risk registers, structured checklists, brainstorming, the Crawford Slip method, and influence diagrams, among others (Chapman, 2001; Raz and Michael, 2001; Lyons and Skitmore, 2004). As for risk evaluation, the probability impact (PI) assessment, Monte Carlos Simulation (MCS), artificial hierarchy process (AHP), multi-regressions, discriminant analysis, and fuzzy analysis have been applied for project risk management (Hsueh et al., 2007; Han et al., 2008; Zayed et al., 2008; Cioffi and Khamooshi, 2009; Lazzerini and Mkrtchyan, 2011). However, many researchers have criticized these kinds of quantitative risk management, which are rarely used in actual projects (Raz and Michael, 2001; Wood and Ellis, 2003; Laryea and Hughes, 2008; Taroun, 2014; Yoo et al., 2017). Practitioners in the industry trust their experience and intuition more than statistical analysis or complex models, asserting that simple numbers and single judgments derived from an academic model cannot explain a whole risk situation and level of severity. They prefer to assess the risk situation themselves, after reviewing all the available information and knowledge, such as internal historical data, external data references, expert advice, and their own experience. Therefore, if practitioners have enough information and experience, they do not adhere to the various available academic approaches. However, construction companies often do not have enough local experts and local practice information for an international construction project. In the case of SMCCs, these shortages are more serious. Thus, a benchmarking approach might be useful to international practitioners because it does not directly judge a risk decision but focuses on providing a helpful reference for rational decisions.

Benchmarking measures performance outcomes of completed projects, which enables a company to continually improve its own competitiveness and sustainability by comparing with competing companies (Yun and Jung, 2017). Benchmarking in construction typically measures key performance indicators such as cost, schedule, productivity, changes, safety, and competition (Yun et al., 2016). For example, the Construction Industry Institute (CII) operates the Benchmarking and Metrics (BM\&M) program that provides norms for best practices of a construction project (CII, 2021). A user can assess an individual project performance based on the norms which consist of mean, median, and quartile cutoffs of similar projects' performances (Lee et al., 2005).

Benchmarking is an effective tool for improvement in project management. It allows a company to understand the current state of a project and to have confidence in expected outcomes by reducing uncertainty based on data-driven analysis (RICS, 2020). Moreover, benchmarking enables industrial practitioners to adopt innovative strategies and solutions to tackle constructionrelated problems (Olawumi and Chan, 2019). Appropriate riskmanagement indicators and sufficient external benchmark data would support SMCCs to evaluate and respond to international project risk.

\section{Research Methodology}

\subsection{Benchmark Framework}

This study attempts to derive a three-phased risk-management benchmark framework for international SMCCs. First, the authors gathered previous studies and developed an initial benchmark framework draft. Over three meetings, 20 experts (thirteen from the industry, seven from academia) with an average of 19.8 years of experience in international construction participated in the review of the risk-management benchmark framework. At the first meeting, the benchmarking framework was approached in two phases: internationalization of company capability and project risk. Although most experts were satisfied overall with the framework, several experts strongly suggested that benchmarking internationalization capability and project risk alone was not enough and that providing risk response information was important for improving international risk management. Therefore, a contract risk benchmark was developed and added as the third phase. 


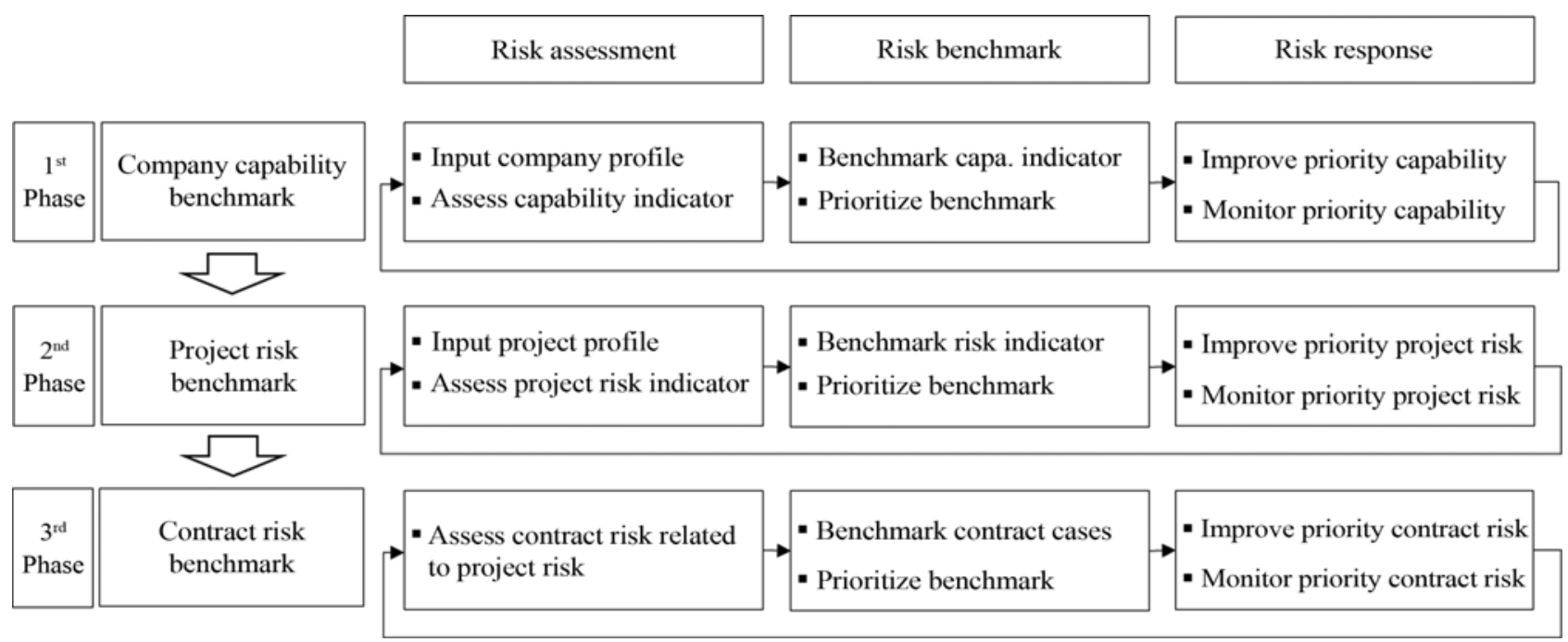

Fig. 2. Risk-Management Benchmark Framework for International SMCC

These framework and benchmark indicators were developed more in the second and third expert meetings. Finally, the threephased risk-management benchmark framework for international SMCCs was developed as shown in Fig. 2.

The first and second phases are comprised of three steps: risk assessment, risk benchmark, and risk response. First, the company or project information is input, and the indicators are measured. Second, the result of the company or project risk assessment is compared with benchmark data and the priority indicator that should be improved for international SMCCs is derived. The third phase provides various examples of contract risk resolutions that correspond to project risks identified in the second phase.

\subsection{Internationalization Capability Benchmark Metrics}

Table 1 shows four performance metrics for internationalization capability: construction, international business, international human resources (HR), and financial. Each performance metric has several subordinate indicators. The indicators of internationalization capability have been identified from previous research and expert interviews. First, from twenty research papers, four indicators and 32 measurements were derived as indicators related to the performance of international construction or SMCC. Next, four indicators and 23 measurements were selected from six experts in the second expert meeting.

\subsubsection{Construction Performance}

Construction performance metrics are used to evaluate the technical capability of an international construction project. These metrics are measured by schedule delays, cost overruns, overseas equipment, defect rates, and incident rates. Managing schedule delays and cost overruns is a fundamental competency for construction companies (Alaghbari et al., 2007). In this study, schedule delays and cost overruns were measured as the average performance value over the last three years. Overseas equipment availability is also an important capability factor; often, necessary equipment is not supplied in local markets (Patel and Vyas,
2011). The defect rate, incident rate, and claim occurrence are measurements for quality management capability.

\subsubsection{International Business Performance}

International business performance expresses how well a company has fulfilled international projects in the past. The construction industry is evaluated empirically based on its performance (Fong and Choi, 2009). This study selected and followed such empirical performance factors as market diversification, product diversification, international revenue ratio, award competitiveness, international network, and client satisfaction as part of its overall parameters. Market diversification and product diversification indicate the number of countries and the number of international projects a company has performed. Diversification is an important factor in enhancing stability in the localization or overseas expansion strategy of construction companies (Han et al., 2010), and the international revenue ratio is found by calculating the percentage the total revenue that is generated by international work. Award competitiveness is the number of wins compared with the number of bid proposals, and the international network shows how robustly and effectively the company has built an overseas network with the owner or general contractor. Finally, client satisfaction indicates the owner's or general contractor's level of satisfaction with past projects and is considered an important factor in the evaluation of the company (Chan and Chan, 2004; Costa et al., 2006; Lu et al., 2010).

\subsubsection{International HR Performance}

For better internationalization, the level and number of internationally experienced and skilled experts are crucial. International HR performance is measured by an international expert ratio, staff training for an international project, technical HR competitiveness, estimate of HR competitiveness, employee productivity, and the average length of continuous service. The international expert ratio indicates the percentage of international projects of experienced employees in a company. Technical and estimated 
Table 1. Benchmark Metrics of Internationalization Capability

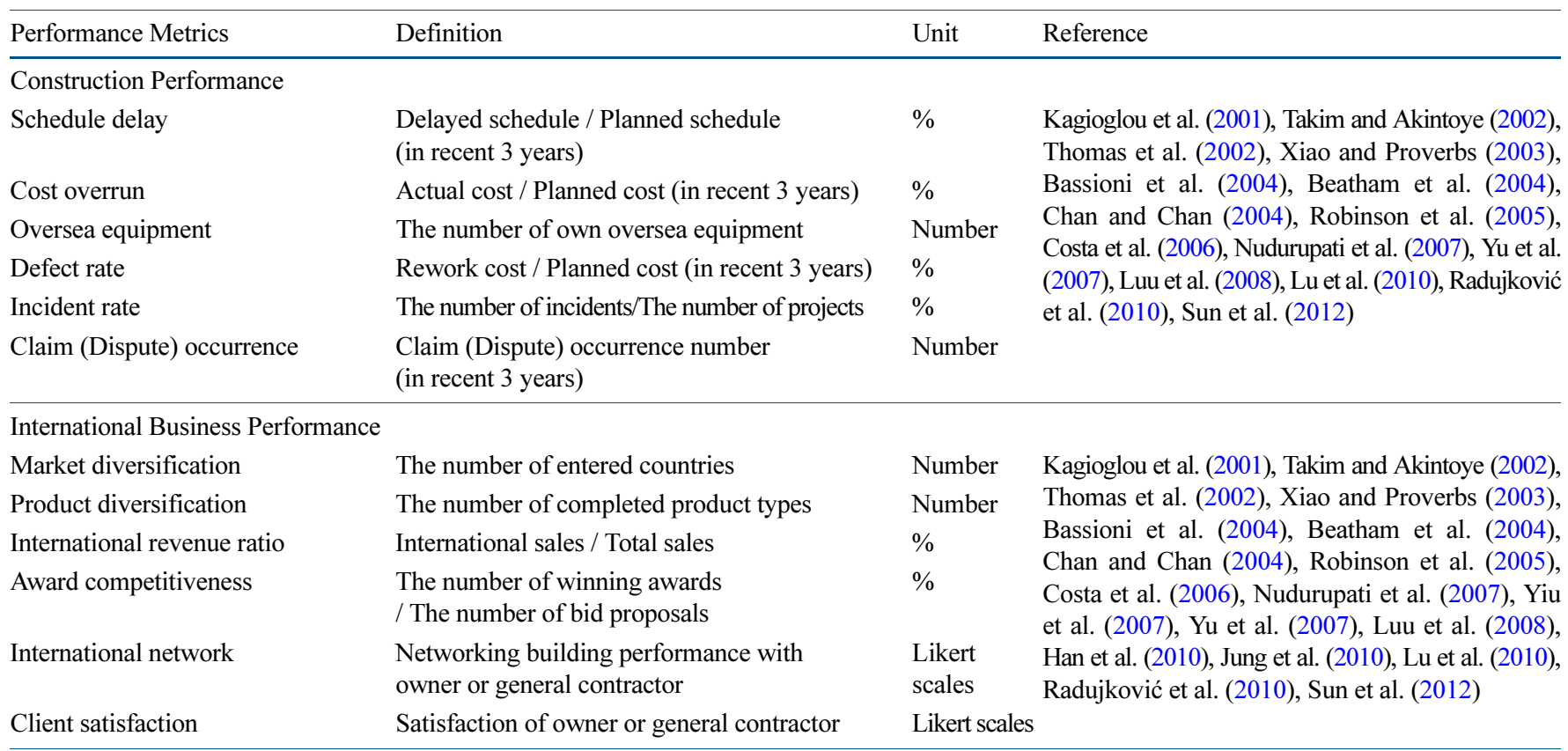

International HR performance

International expert ratio

Staff training for international

project

Technical HR competitiveness

Estimate HR competitiveness

Employee productivity

Average of continuous service

International project experienced employee /

Total employee

Satisfaction of staff training for international projects

The number of technical experts

/ Total employee

The number of estimate experts

/ Total employee

Total revenue / Total employee

Average of continuous service

per employee
$\% \quad$ Takim and Akintoye (2002), Thomas et al. (2002), Sexton and Barrett (2003), Beatham et al. (2004), Costa et al. (2006), Nudurupati et al. (2007), Yiu

$\begin{array}{ll}\text { scales } & \text { et al. (2007), Yu et al. (2007), Luu et al. (2008), } \\ \% & \text { Radujković et al. (2010), Sun et al. (2012) }\end{array}$ $\begin{array}{ll}\text { scales } & \text { et al. (2007), Yu et al. (2007), Luu et al. } \\ \% & \text { Radujković et al. (2010), Sun et al. (2012) }\end{array}$

$\%$

$1,000 \$$

Year

\begin{tabular}{lll}
\hline Financial Performance & \\
Current ratio & Current assets / Current liabilities & $\%$ \\
Debt ratio & Total debts / Total assets & $\%$ \\
Return on revenues & Operating income / Revenue & $\%$ \\
Revenue growth rate & Current year's revenue/Previous year's revenue & $\%$ \\
Operating income growth rate & Current year's operating income & $\%$ \\
& / Previous year's operating income &
\end{tabular}

HR competitiveness are considered, as both measurements are important aspects of an international project (Nguyen and Hadikusumo, 2017). Staff training for an international project is also important given its impact on future growth potential (Tabassi and Bakar, 2009). Employee productivity refers to the revenue generated per employee. The average of continuous service is calculated by the total length of employee service to a company divided by the total number of employees. This measurement shows the stability of the retention rate expert because it costs to educate and familiarize newly recruited employees (Tabassi and Bakar, 2009).

\subsubsection{Financial Performance}

Financial performance is a necessary indicator to evaluate company performance in any industry. In particular, financial stability is essential for SMCCs because they are prone to bankruptcy due to their lack of financial leverage (Westhead et al., 2001; Lu et al., 2010; Jang et al., 2019). This indicator is measured by a company's current ratio, debt ratio, return on sales, sales growth rate, and operating income growth rate. These measurements are generally used to assess a company's financial position. The current ratio and debt ratio are calculated by current assets of current liabilities and total debts of total assets, respectively. Return on sales is the ratio used to evaluate a company's operational efficiency. Sales growth rate and operating income growth rate indicate the amount of growth compared with the previous year. 


\subsection{International Project Risk-Assessment Benchmark Metrics}

Table 2 shows the benchmark indicator for subcontracting project risk. The indicators and corresponding measurements have been identified from previous research. Sixteen research papers concerning international construction project risk and subcontracting risk were reviewed. Consequently, in this study, a total of twelve indicators and 68 measurements have been identified and

Table 2. Benchmark Metrics of Subcontracting Project Risk

\begin{tabular}{lll}
\hline Risk Metrics $\quad$ Measurement & Reference \\
\hline
\end{tabular}

Country Perspective

Political

Civil war/terror/regime change, Corruption and collusion, Change

Economic

Currency uncertainty, Interest rate uncertainty

Social \& Infra

Cultural difference, Civil complaints, Poor living environment, Social legitimacy for projects

Project Perspective

Owner

Contract

Resource

Physical

Unfavorable geographical accessibility, Poor infra \& logistics condition, Geological uncertainty, Weather and climate uncertainty

Contractor

Unclear work scope, Unclear payment condition, Unclear retention money, Poor collaboration, Work practice and routine difference, Poor language risk, Contractor's construction ability financing resources of owner, Administrative approval and licensing delays, Informal request by owner

Insufficient period for bid preparation, Insufficient period for completion, Unreasonable local contents, Unfavorable retained earning transfer, Unfavorable tax and tariff treaty, Unfavorable inflation compensation, Unfavorable security clause, Unfavorable payment condition, Unfavorable liquidated damage, Unfavorable payment currency, Unfavorable claim and arbitration

Staff supply difficulty from host country, Material supply difficulty from host country, Equipment supply difficulty from host country in laws, Imperfect institution

Han et al. (2007), Jha and Devaya (2008), Bu-Qammaz et al. (2009), Zhao et al. (2013), Yildiz et al. (2014), El-Sayegh and Mansour (2015), Hwang et al. (2017), Jung and Han (2017), Yoo et al. (2017), Li et al. (2020) Jha and Devaya (2008), Ng and Tang (2008), Zhao et al. (2013), Hwang et al. (2017), Jung and Han (2017), Yoo et al. (2017), Li et al. (2020)

Han et al. (2007), Bu-Qammaz et al. (2009), Zhao et al. (2013), El-Sayegh and Mansour (2015), Hwang et al. (2017), Jung and Han (2017), Tan et al. (2017), Yoo et al. (2017), Li et al. (2020)

Han et al. (2007), Jha and Devaya (2008), Bu-Qammaz et al. (2009), Ling et al. (2009), Zhao et al. (2013), Yildiz et al. (2014), El-Sayegh and Mansour (2015), Hwang et al. (2017), Jung and Han (2017)

Packham et al. (2003), Han et al. (2007), Eom et al. (2008), Jha and Devaya (2008), Ng and Tang (2008), Bu-Qammaz et al. (2009), Ling et al. (2009), Zhao et al. (2013), Yildiz et al. (2014), El-Sayegh and Mansour (2015), Hwang et al. (2017), Jung and Han (2017), Tan et al. (2017)

Jha and Devaya (2008), Bu-Qammaz et al. (2009), Yildiz et al. (2014), El-Sayegh and Mansour (2015), Hwang et al. (2017), Jung and Han (2017), Yoo et al. (2017), Li et al. (2020)

Han et al. (2007), Bu-Qammaz et al. (2009), Zhao et al. (2013), Yildiz et al. (2014), El-Sayegh and Mansour (2015), Hwang et al. (2017), Jung and Han (2017), Yoo et al. (2017), Li et al. (2020)

Packham et al. (2003), Han et al. (2007), Eom et al. (2008), Jha and Devaya (2008), Ng and Tang (2008), Bu-Qammaz et al. (2009), Ling et al. (2009), Zhao et al. (2013), Yildiz et al. (2014), El-Sayegh and Mansour (2015), Hwang et al. (2017), Jung and Han (2017), Tan et al. (2017)

Capability Perspective

Organizational

Leadership of project manager, Headquarters' support level, P.E and $\mathrm{Ph} . \mathrm{D}$. retention level, Collaboration and flexibility, Communication capability, Labor management capability

Construction management

Cost management capability, Schedule management capability, Quality management capability, Resource management capability, Labor training capability, Claim management capability, Contract management capability, Document management capability, IT based project management capability, Safety management capability, Environment management capability

Localization Local network capability, Information acquisition capability, Host country's experience of project manager, Overall localized level

Technical Construction method experience, Inadequate understanding of standards, Rework due to errors and defects, Lack of experienced labor, New construction method capability
Han et al. (2007), Jha and Devaya (2008), Ng and Tang (2008), Ling et al. (2009), Yildiz et al. (2014), Hwang et al. (2017), Jung and Han (2017)

Han et al. (2007), Eom et al. (2008), Jha and Devaya (2008), Ng and Tang (2008), Bu-Qammaz et al. (2009), Ling et al. (2009), Zhao et al. (2013), Yildiz et al. (2014), Jung and Han (2017), Yoo et al. (2017)

Han et al. (2007), Yildiz et al. (2014), Jung and Han (2017)

Packham et al. (2003), Han et al. (2007), Eom et al. (2008), $\mathrm{Ng}$ and Tang (2008), Yildiz et al. (2014), El-Sayegh and Mansour (2015), Jung and Han (2017) El-Sayegh and Mansour (2015), Hwang et al. (2017), 
evaluated using a five-point Likert Scale. A brief description of each indicator is presented below.

\subsubsection{Country Risk}

Country risk has been regarded as the most important risk for an international project (Ling et al., 2009; Zhao et al., 2013; Yildiz et al., 2014; El-Sayegh and Mansour, 2015; Yoo et al., 2017; Li et al., 2020; Zhu et al., 2021). This study divided country risk into political, economic, social, and infrastructure risk. Political risk arises from an act by the government of the host country that could negatively affect project performance. It is widely considered in previous research as one of the most significant project risk metrics (Yildiz et al., 2014; Yoo et al., 2017). This research evaluates the political risk using four measurements: civil war/ terror/regime change; corruption and collusion; change in law; and imperfect institution. The macro-economic condition has a huge impact on the overall construction industry and could affect subcontractor profit performance regardless of their capability (Zhao et al., 2013; Yoo et al., 2017; Kim et al., 2019). This research includes currency uncertainty and interest-rate uncertainty as measurements of economic risk. Also, social factors, such as differences in culture and language among partners or stakeholders, could disrupt interaction and communication, which could negatively affect project performance (Bu-Qammaz et al., 2009; Jung and Han, 2017; Yoo et al., 2017; Li et al., 2020). This research includes cultural differences, civil complaints, poor living environment, and social legitimacy for projects as measurements.

\subsubsection{Project Condition Risk}

Country risk is not easily managed through contract or organizational capability, whereas project condition risk can be controlled through such capabilities. This study comprises the following project risks: owner, contract, resource, physical, and contractor. Owner risk is related to the project management capability of the owner. Many previous types of research have stated that project implementation and performance could be impeded or promoted according to the owner's experience and capability (El-Sayegh and Mansour, 2015; Hwang et al., 2017). This research evaluates owner risk using the owner's management capability, the design accuracy they provided, whether specifications provided by the owner are insufficient, the owner's financing stability, administrative approval and licensing delays, and informal requests by the owner

Contract risk entails the terms and clauses of the contract that could be made against project performance. Especially for an SMCC, which has little experience in international projects and host countries, contracts are carefully checked and could adversely affect project performance (Ling et al., 2009). This research uses twelve measurements to evaluate contract risk.

Resource risk involves the likelihood of procuring the necessary labor, materials, and equipment with sufficient quality to implement the project. It is not easy, perhaps, to procure these resources for an international project, according to the host country (Jha and Devaya, 2008; El-Sayegh and Mansour, 2015; Yoo et al., 2017;
Li et al., 2020). This research evaluates the difficulties encountered with staff, materials, and equipment supplies of resources from the host country.

Physical risk includes unfavorable geographical accessibility, poor infra- and logistics conditions, geological uncertainty, and weather and climate uncertainty. Project implementation could be disturbed without investigation and countermeasures, which should be done at the initial stage of the project (Bu-Qammaz et al., 2009; Yildiz et al., 2014; Yoo et al., 2017). Many previous research studies have stated the importance of capability and the relationship of the project partner (Packham et al., 2003; Ling et al., 2009). This study evaluates the lack of clarity in work scope; payment conditions; money retention; poor collaboration, work practices, and routine differences; poor language risk; and contractor's construction ability for contractor risk.

\subsubsection{Capability Risk}

The first phase deals with a company's capability, but the second phase focuses on the project organization's capability, which is comprised of organizational, management, localization, and technical factors. Organizational risk involves internal organizational structure and subcontractor resources. This research includes the project manager's leadership, headquarters' support level, P.E. and Ph.D. retention levels, collaboration and flexibility, communication capability, and labor management capability for organizational risk. Management risk is about the overall project management capability of the subcontractor. Lack of management capability could cause problems with project implementation, such as duration, cost, and quality (Ng and Tang, 2008; Yildiz et al., 2014; Yoo et al., 2017). This research includes eleven measurements to evaluate the management capability of the subcontractor. Localizing efforts within the host country is important for international construction projects, and can be created through localization to acquire information and implement the project (Han et al., 2007; Yildiz et al., 2014). This research has measured the local network capability, information acquisition capability, experience of the host country's project manager, and an overall localized level to evaluate the localization risk. If the subcontractor has a technical problem with the company that carries out the construction work directly, it could seriously affect overall project performance. Five measurements have been used to evaluate the technical risk: construction method experience; inadequate understanding of standards; rework due to errors and defects; lack of experienced labor; and new construction method capability (Yildiz et al., 2014; El-Sayegh and Mansour, 2015; Yoo et al., 2017).

\subsection{Data Collection and Quantification}

This study collected benchmark data from the internationally experienced experts working at SMCCs in Korea. For the collection of capability benchmark data, survey questionnaires were distributed to 236 SMCCs, and 41 responses were compiled. Thus, the response rate was $17.4 \%$. The average international revenue over three years was M\$19.5, and the average international revenue portion of the firms' total revenue was $33.4 \%$. For a 
collection of subcontracting project risk data, survey questionnaires were distributed to 241 subcontractors' international projects, and 49 responses were received. The average cost of the projects was M\$ 468, and the average project duration was 20 months. Twenty-four projects suffered cost overruns, 15 of which recorded a cost overrun rate higher than $30 \%$. Sixteen projects also experienced delays in contractual schedules.

Each benchmark data has a different scale. Thus, quantification of these different scale metric measurements is required to properly evaluate and compare them with various project types and characteristics (Yun et al., 2016). The quantification process consists of the following three steps: 1) Normalizing measurements using mean and standard deviation, 2) Weighting of each measurement, 3) Ranking of each normalized measurement value.

In the first step, mean and standard deviation were calculated for each measurement. Because many capability measurements are absolute metrics, such as construction and business performance, they require normalization. Another reason for normalization is to provide more useful and explicit information to compare different benchmark indicators. Based on these mean and standard deviations for each measurement, the equation for standardization is equal to Eq. (1), where $Z_{i j}$ denotes the normalized measurement of given scores $\left(\mathrm{x}_{i j}\right)$ in $j$ th measurement of the $i^{\text {th }} \mathrm{SMCC}, \mathrm{x}_{i j}$ denotes each scores of $j^{\text {th }}$ measurement of the $i^{\text {th }}$ SMCC, $\bar{x}_{j}$ denotes the mean of $j^{\text {th }}$ measurement, and $\sigma_{j}$ denotes the standard deviation of $j^{\text {th }}$ measurement:

$$
Z_{i j}=\frac{x_{i j}-\bar{x}_{j}}{\sigma_{j}}
$$

Since each indicator has different numbers and types of unit measurements, the value of the normalization score is in the range of zero to one hundred before the addition of the measurements. The equation for converting the normalized measurement to the range of zero to one hundred is Eq. (2), where 1.67 is one sigma deviation in normal distribution and $\mathrm{X}_{i j}$ is the benchmark score that has the range of zero to one hundred:

$$
X_{i j}=1.67 \times Z_{i j}+50 \text {. }
$$

The benchmark score of each indicator should be weighted because each company and project has a different context and situation; this benchmark evaluation can be modified according to the user's estimation of the severity of each situation. Finally, the benchmark rankings are calculated to show the priority of each benchmarking score.

\section{International Contract Management Benchmark}

This study provides contractual risk-management benchmark

\begin{tabular}{|c|c|c|c|}
\hline \multicolumn{2}{|l|}{ Indicator } & \multirow{2}{*}{$\begin{array}{l}\text { Case description } \\
\text { Change in law related to tax }\end{array}$} & \multirow{2}{*}{$\begin{array}{l}\text { Num. of cases } \\
2\end{array}$} \\
\hline Country Perspective & Political & & \\
\hline & & Change in law related to working hour & 2 \\
\hline & Economic & Unstable currency & 6 \\
\hline & & Change of macroeconomic condition & 1 \\
\hline & & Cultural differences & 2 \\
\hline & & Difference of labor regulation & 1 \\
\hline & & Work permit and minimum wage rate & 1 \\
\hline \multirow[t]{10}{*}{ Project Perspective } & Owner & Delay in payment by employer & 5 \\
\hline & & Delay in material supply by employer & 2 \\
\hline & & Insufficient design document provided by employer & 2 \\
\hline & & Negligence of local employer's authority & 2 \\
\hline & & Delay in co-financing by employer & 1 \\
\hline & & Improper engineer selection & 1 \\
\hline & & Impossibility of balance payment after project suspension & 1 \\
\hline & & Insertion of the clause that rejects the excessive change order & 1 \\
\hline & & Non-payment of compensation related to delay in site preparation & 1 \\
\hline & & Unfavorable decision making by multiple employers & 1 \\
\hline
\end{tabular}

Table 3. International Contract Risk Management Cases 
Table 3. (continued)

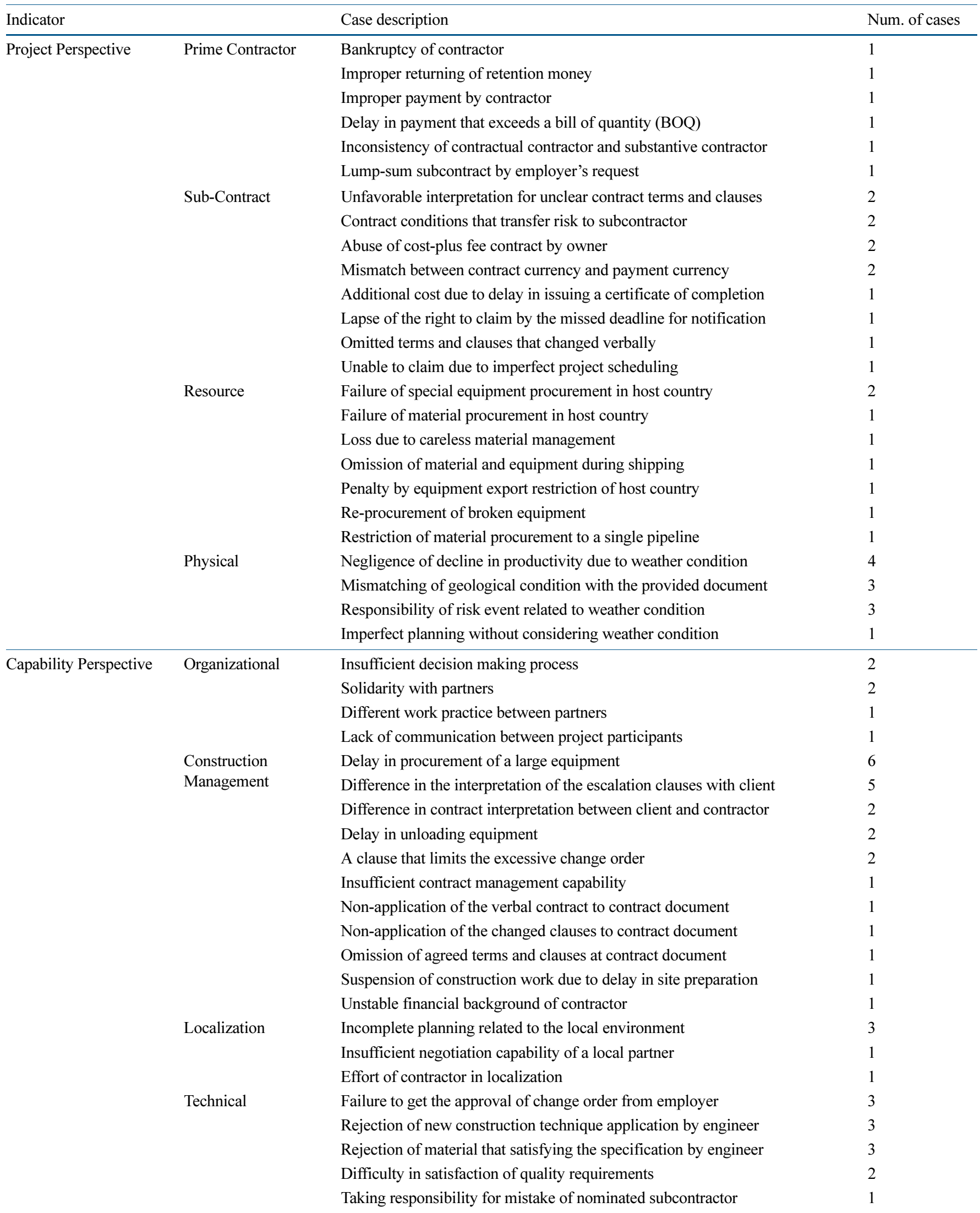


information for risk-response management. The contract management benchmark provides 134 contractual cases, which are categorized into nine sub-groups and 73 topics as shown in Table 3. Nine sub-groups were the same as $2^{\text {nd }}$ phase risk benchmarking; if the $2^{\text {nd }}$ benchmark shows that some metrics are poor, the user can refer to the corresponding benchmark cases. Some topics have several cases, and other topics only one. These cases were gathered through interviews and reports by the six international contract experts, who have on average 25 years of experience on international projects. All cases do not include the name of the owner, prime-contactor and subcontractor because of confidentiality compliance. These also do not include specific numbers like price, volume, and date, depending on the individual cases. Some cases just include the name of country or product type.

\section{Illustrative Case Applications}

These illustrative case applications aim to express the practical validation of this risk-management benchmark framework. Among the collected benchmark information, this study selected three international SMCCs and their subcontracting projects as shown in Table 4. Each case has a different capability and risk situation. SMCC A has a high internalization capability that enables them to deal with a higher risk level of a subcontracting project. SMCCs B and C have a weak level of internalization capability, implying that they can manage with a moderate- or low-risk level of subcontracting projects, respectively. These different contexts show how they can utilize this risk-management benchmark framework according to their unique situation.

\subsection{Internationalization Capability Benchmark}

Each SMCC had a different internationalization capability. Each company was required to assess and review which factors were considered comparatively weak and how much these risk factors needed to be improved. Fig. 3 and Table 5 show high benchmarking internationalization capability. SMCC A was a highly internationalized subcontractor that had earned $25 \%$ international revenue of total revenue over the past three years, which was the highest international revenue ratio among the three firms. They recorded ranking first in cost and schedule management performance as shown in Table 5. In addition, they experienced the use of many types of products in various countries, even though they recorded the smallest revenue among the three cases. Of the 41 benchmark companies, this firm ranked $2^{\text {nd }}$ in the total internationalization capability score and yielded a higher profit in many projects. However, this company needed to improve several financial issues as shown in Table 5. For example,

Table 4. Samples Profiles

\begin{tabular}{llll}
\hline & SMCC A & SMCC B & SMCC C \\
\hline 3yrs revenue (M\$) & 61 & 909 & 315 \\
3yrs international revenue (M\$) & 16 & 106 & 32 \\
3yrs debit ratio (\%) & 30.8 & 86.3 & 184.6 \\
Employer number & 153 & 396 & 100 \\
Entered countries & Saudi Arabia, Vietnam, & Singapore, Malaysia, Hong Kong, & Saudi Arabia, UAE, Algeria \\
Case country & Bangladesh & Qatar, Kuwait & Algeria \\
Case product & Saudi Arabia & Vietnam & Building \\
Contract type & Power plant & Road & Cost-plus fee \\
\hline
\end{tabular}

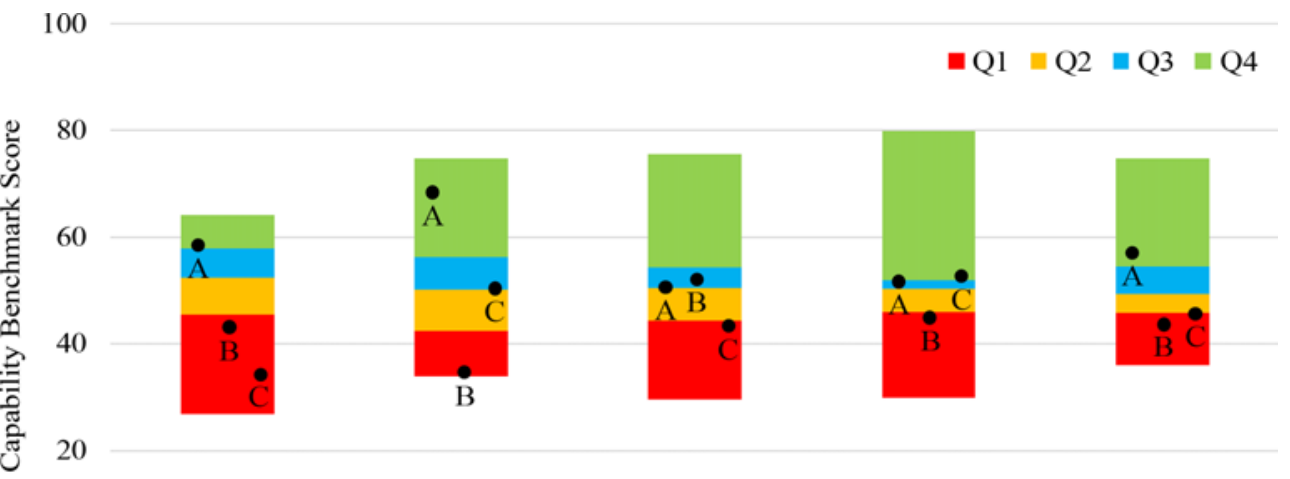

0

$\begin{array}{lcccc}\begin{array}{l}\text { Construction } \\ \text { Performance }\end{array} & \begin{array}{c}\text { Int'l Business } \\ \text { Performance }\end{array} & \begin{array}{c}\text { International HR } \\ \text { Performance }\end{array} & \begin{array}{c}\text { Financial } \\ \text { Performance }\end{array} & \text { Total Score } \\ & & \end{array}$

Fig. 3. Metric Distribution of Internationalization Capability 
Table 5. Benchmark Metric Details of Internationalization Capability

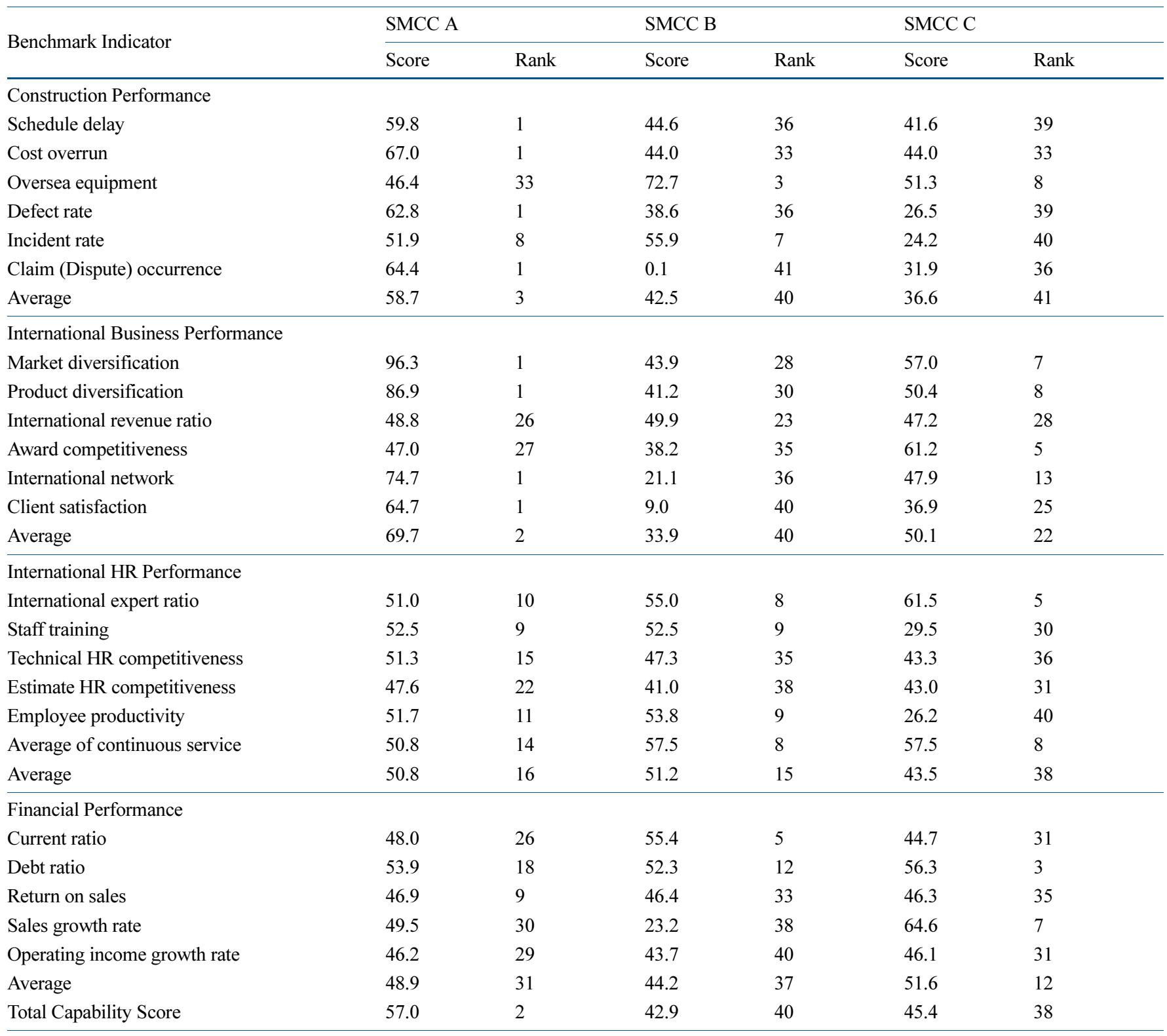

they were short of working capital and were earning a low growth rate compared to other companies.

SMCC B ranked $40^{\text {th }}$ in the internationalization capability score, even though they earned larger revenues and were thought of as being one of the strong leading subcontractors in the domestic market. This firm has attempted to do overseas business in several countries but frequently failed to win bid awards or made a loss in many projects. Nevertheless, this company continued to seek large subcontracting project awards because they wanted to overcome their low revenue growth rate in the domestic market. Hence, they needed to benchmark which capabilities were weak and how much they would have to improve for better performance levels. As shown in Table 5, this firm achieved poor performance in almost every indicator compared to other SMCCs, which means that they had to consider not going abroad before entirely improving their internationalization capability or selecting only risk-free projects.

SMCC $\mathrm{C}$ had a similar level of capability with SMCC B. They also ranked very poorly in construction, international business, international human resource, and financial performance. One of the interesting points, however, was that SMCCs B and C had different internationalization strategies for realizing better capability. SMCC C could recognize that they were relatively noncompetitive in the areas of construction performance and international human resource performance. So, they were used to selecting low-risk international projects and tended to secure good profit performance, which is explained in more detail in the next section. 


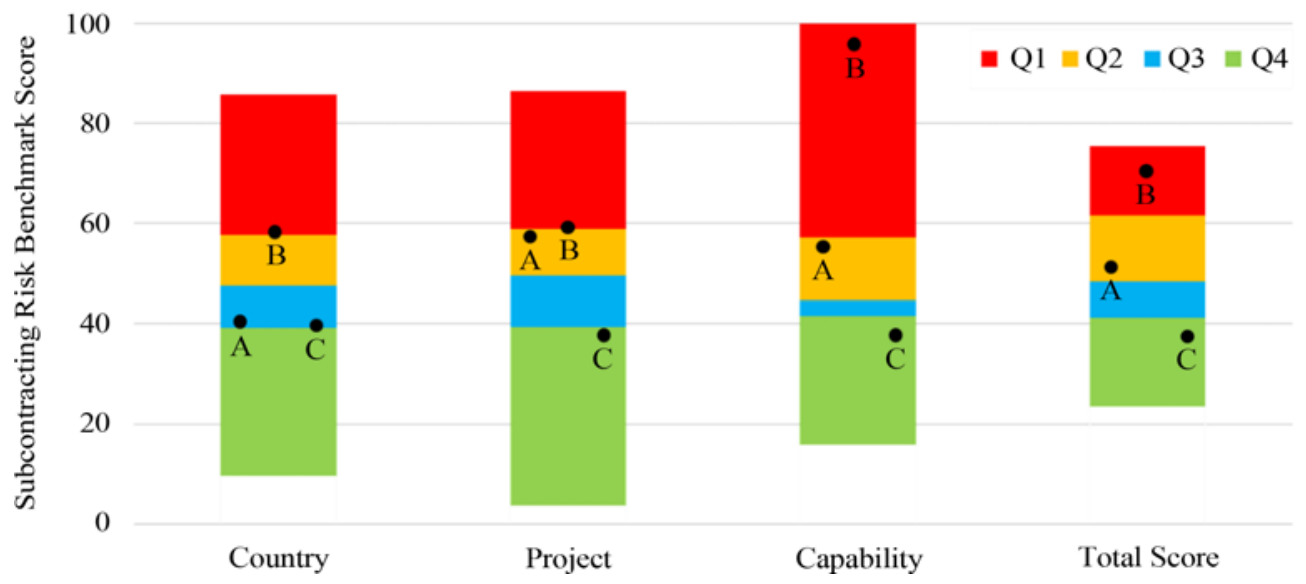

Fig. 4. Metric Distribution of International Project Risk Assessment

\subsection{International Project Risk-Assessment Benchmark}

Each international project has a different risk level. Each SMCC has to review how much the given project is risky and what risk has to be responded to in advance. In addition, each SMCC has to select the appropriate project, considering whether or not they have enough capability to manage its given risk level. SMCC A had a strong internationalization capability, but SMCC B and C had a relatively weak internationalization capability, as mentioned in the previous section. SMCC A selected the medium-high risk project positioned in the second quarter as shown in Fig. 4. SMCC A evaluated contractor risk, contract risk, and owner risk as higher levels. As they have experienced many other projects in the same country of the given project and had been in a relationship with the contractor for 15 years, they comprehended this kind of risk situation as acceptable. Accordingly, they knew how they had responded to these risks in the past and they signed lump-sum contracts yielding a high profit. The benchmark metrics of Table 6 also suggest that, for better performance, SMCC A needed to improve construction management and localization capability in this targeted project. By contrast, SMCC B chose a very high-risk project even though they did not have enough internationalization capability; country and project risk was also very high, and they had a poor relationship with the contractor. Moreover, the contractor had difficulty in controlling project risks and to make a profit, which impacted the profit of SMCC B. The risks related to technical and organizational capability ranked first. If they had these kinds of benchmark references, they could compare their risk level with other projects and might not have selected this type of project. SMCC C executed a project with a lower level-of-risk score, recognizing that they did not have a strong internationalization capability. So, they selected a low-risk project as shown in Table 6 and signed under the condition of a cost-plus fee contract. They also had a good relationship with the prime contractor for more than six years. These kinds of positive situations enabled SMCC C to execute the given project successfully and to earn a profit.
Table 6. Benchmark Metric Details of International Subcontracting Project Risk

\begin{tabular}{|c|c|c|c|c|c|c|}
\hline \multirow{2}{*}{$\begin{array}{l}\text { Benchmark } \\
\text { Indicator }\end{array}$} & \multicolumn{2}{|c|}{$\begin{array}{l}\text { Project A } \\
\text { by SMCC A }\end{array}$} & \multicolumn{2}{|c|}{$\begin{array}{l}\text { Project B } \\
\text { by SMCC B }\end{array}$} & \multicolumn{2}{|c|}{$\begin{array}{l}\text { Project C } \\
\text { by SMCC C }\end{array}$} \\
\hline & Score & Rank & Score & Rank & Score & Rank \\
\hline \multicolumn{7}{|l|}{ Country } \\
\hline Political & 42.5 & 18 & 42.5 & 18 & 42.5 & 18 \\
\hline Economic & 38.9 & 21 & 69.3 & 3 & 38.9 & 21 \\
\hline Social \& Infra & 46.0 & 16 & 62.5 & 9 & 40.4 & 22 \\
\hline Average & 42.5 & 27 & 58.1 & 8 & 40.6 & 28 \\
\hline \multicolumn{7}{|l|}{ Project } \\
\hline Owner & 57.9 & 9 & 79.4 & 3 & 40.1 & 22 \\
\hline Contract & 61.3 & 7 & 50.9 & 16 & 40.5 & 24 \\
\hline Resource & 42.1 & 19 & 60.9 & 6 & 42.1 & 19 \\
\hline Physical & 41.5 & 18 & 56.4 & 8 & 34.1 & 32 \\
\hline Contractor & 91.2 & 2 & 56.3 & 8 & 40.9 & 20 \\
\hline Average & 58.8 & 9 & 60.8 & 7 & 39.5 & 29 \\
\hline \multicolumn{7}{|l|}{ Capability } \\
\hline Organizational & 41.6 & 17 & 99.9 & 1 & 34.9 & 32 \\
\hline $\begin{array}{l}\text { Construction } \\
\text { management }\end{array}$ & 74.5 & 3 & 92.4 & 1 & 41.9 & 21 \\
\hline Localization & 58.8 & 8 & 79.4 & 2 & 38.3 & 19 \\
\hline Technical & 50.1 & 11 & 99.9 & 1 & 42.2 & 22 \\
\hline Average & 56.3 & 9 & 97.8 & 1 & 39.3 & 30 \\
\hline Total Risk Score & 52.5 & 13 & 72.2 & 1 & 39.8 & 31 \\
\hline
\end{tabular}

\subsection{International Contract Management Benchmark}

Each SMCC could obtain contract management cases in the third phase benchmark corresponding to the high-risk metric in Table 6 . SMCC A evaluated that prime contractor risk and construction management risk were high. SMCC A could benchmark the 29 cases from these two risk sub-groups. In comparison, SMCC B confirmed that their project risk was very high in Table 6. In particular, technical risk, organizational risk, construction management risk, localization risk, owner risk, and economic risk were evaluated as high. SMCC B could obtain the 85 cases 
corresponding to these five high-risk groups from Table 3 .

For example, SMCC B could benchmark the two cases of "rejection of material satisfying the specification by engineer" in the technical risk sub-group. One case indicated that a contract condition to sand material requests only the required quality but not the sand source. So, the subcontractor submitted the approval document of river sand with a method statement that improved the quality of river sand. However, the engineer declined the river sand regardless of the improvement method and insisted on only approving mountain sand. Therefore, the subcontractor suffered losses by purchasing expensive mountain sand far from the construction site. However, in this case, if the subcontractor had raised the claim, the subcontractor might have won. They did not know about this contract practice. Another similar case was that the subcontractor knew this kind of material source issue and they suggested the provisional sum to the contractor: "if the mountain sand cannot be obtained within $\mathrm{OO} \mathrm{km}$, the river sand with the qualified test can be used or the mountain sand can be utilized with the additional payment". This suggestion was accepted by the contractor.

Another example was the case of an unstable currency in the economic risk group for SMCC B. A Korean subcontractor contracted with the local prime contractor with a $100 \%$ local currency payment. This subcontractor planned that $80 \%$ of their expenditure was local currency. So, they underestimated this currency risk. However, the financial crisis happened in 2009, which significantly decreased the value of the local currency. Moreover, the subcontractor used a USD loan for construction cash flow, which impacted the significant loss. So, this case suggests that, if possible, the payment of local currency ratio should be similar to the expenditure of local currency and the construction loan had better be derived from the same currency ratio.

\section{Conclusions}

This study attempts to provide a risk-management benchmark framework and practical information to international SMCCs. This benchmark approach to project risk management is the first such trial to the best of the authors' knowledge. This study should be valuable for the following reasons: First, international SMCCs usually have limited project experience in a foreign country, so they need to obtain and compare external project references for their own decision-making and risk management. Second, this study provides three-phased benchmark references for different situations. Chief Executive Officers (CEOs) and executive management can consider the results to determine whether they should go abroad or check their competitiveness level. Project professionals can review project risk levels when they prepare a proposal or subcontract. Additionally, project professionals can develop risk response strategies based on the contract cases related to high-risk score metrics. Third, this study attempts to provide a qualitative benchmark reference, which is a new approach in benchmark research. If the number of cases increases, best practices considering various cases could be very useful for references and developing risk-response strategies.

This study illustrates the validation of this benchmarking framework using three actual companies and projects. Highcapability subcontractors can control high-risk projects, but for low-capability subcontractors, it is not easy to manage high-risk projects. These examples show which organizational capability and project risk factors must be improved. Moreover, these highrisk items can be prepared through the link with the contractmanagement benchmark reference. This framework does not define the weight of metric indicators because all companies and projects have different situations and preferences. So, the users can improve the benchmark accuracy using a customized weight of metric indicators.

Even though this framework has many strengths, as mentioned above, this study has several limitations. First, this framework must increase the number of benchmark data. Approximately 50 companies and projects are insufficient to generalize benchmark metric depending on delivery and product types. More cases are necessary to explain more complex and different contract situations. Second, the second phase uses the Likert Scale. Although this measuring method is popular, the practitioners might feel that the input and results look too subjective. Therefore, using an absolute or descriptive scale for the next updated framework is recommended.

\section{Acknowledgments}

This research was supported by Basic Science Research Program through the National Research Foundation of Korea (NRF) funded by the Ministry of Education (No. NRF-2020R1A2C1012739).

\section{ORCID}

Not Applicable

\section{References}

Ahn CR, Lewis P, Golparvar-Fard M, Lee S (2013) Integrated framework for estimating, benchmarking, and monitoring pollutant emissions of construction operations. Journal of Construction Engineering and Management 139(12):A4013003, DOI: 10.1061/(ASCE)CO.19437862.0000755

Alaghbari W, Razali AKM, Salim A, Ernawati (2007) The significant factors causing delay of building construction projects in Malaysia. Engineering, Construction and Architectural Management 14(2): 192-206, DOI: 10.1108/09699980710731308

An X, Zhou L, Liu Z, Wang C, Li P, Li Z (2021) Dataset and benchmark for detecting moving objects in construction sites. Automation in Construction 122:103482, DOI: 10.1016/j.autcon.2020.103482

Baloi D, Price ADF (2003) Modelling global risk factors affecting construction cost performance. International Journal of Project Management 21(4):261-269, DOI: 10.1016/S0263-7863(02)00017-0

Barber E (2004) Benchmarking the management of projects: A review of current thinking. International Journal of Project Management 22(4):301-307, DOI: 10.1016/j.ijproman.2003.08.001

Bassioni HA, Price ADF, Hassan TM (2004) Performance measurement 
in construction. Journal of Management in Engineering 20(2):4250, DOI: 10.1061/(ASCE)0742-597X(2004)20:2(42)

Beatham S, Anumba C, Thorpe T, Hedges I (2004) KPIs: A critical appraisal of their use in construction. Benchmarking: An International Journal 11(1):93-117, DOI: 10.1108/14635770410520320

Bu-Qammaz AS, Dikmen I, Birgonul MT (2009) Risk assessment of international construction projects using the analytic network process. Canadian Journal of Civil Engineering 36(7):1170-1181, DOI: 10.1139/L09-061

Chan APC, Chan APL (2004) Key performance indicators for measuring construction success. Benchmarking: An International Journal 11(2):203-221, DOI: 10.1108/14635770410532624

Chang T, Deng X, Hwang BG, Zhao X (2019) Improving quantitative assessment of political risk in international construction projects: The case of chinese construction companies. Journal of Construction Engineering and Management 145(12):04019083, DOI: 10.1061/ (ASCE)CO.1943-7862.0001738

Chapman RJ (2001) The controlling influences on effective risk identification and assessment for construction design management. International Journal of Project Management 19(3):147-160, DOI: 10.1016/S0263-7863(99)00070-8

Choi J, Leite F, Oliveira DP (2020) BIM-based benchmarking for healthcare construction projects. Automation in Construction 119:103347, DOI: 10.1016/j.autcon.2020.103347

CII (2021) Benchmarking \& metrics. Construction Industry Institute (CII), Retrieved October 13, 2021, https://www.construction-institute.org/ resources/knowledgebase/best-practices/benchmarking-metrics

Cioffi DF, Khamooshi H (2009) A practical method of determining project risk contingency budgets. Journal of the Operational Research Society 60(4):565-571, DOI: 10.1057/palgrave.jors.2602586

Costa DB, Formoso CT, Kagioglou M, Alarcón LF, Caldas CH (2006) Benchmarking initiatives in the construction industry: Lessons learned and improvement opportunities. Journal of Management in Engineering 22(4):158-167, DOI: 10.1061/(ASCE)0742-597X(2006) 22:4(158)

Deng X, Low SP, Li Q, Zhao X (2014) Developing competitive advantages in political risk management for international construction enterprises. Journal of Construction Engineering and Management 140(9): 04014040, DOI: 10.1061/(ASCE)CO.1943-7862.0000836

El-Mashaleh MS, Rababeh SM, Hyari KH (2010) Utilizing data envelopment analysis to benchmark safety performance of construction contractors. International Journal of Project Management 28(1):6167, DOI: 10.1016/j.ijproman.2009.04.002

El-Sayegh SM, Mansour MH (2015) Risk assessment and allocation in highway construction projects in the UAE. Journal of Management in Engineering 31(6):04015004, DOI: 10.1061/(ASCE)ME.19435479.0000365

Elsayegh A, El-adaway IH (2021) Collaborative planning index: A novel comprehensive benchmark for collaboration in construction projects. Journal of Management in Engineering 37(5):04021057, DOI: 10.1061/(ASCE)ME.1943-5479.0000953

Eom CS, Yun SH, Paek JH (2008) Subcontractor evaluation and management framework for strategic partnering. Journal of Construction Engineering and Management 134(11):842-851, DOI: 10.1061/ (ASCE)0733-9364(2008)134:11(842)

Fidan G, Dikmen I, Tanyer AM, Birgonul MT (2011) Ontology for relating risk and vulnerability to cost overrun in international projects. Journal of Computing in Civil Engineering 25(4):302-315, DOI: 10.1061/(ASCE)cp.1943-5487.0000090

Fong PSW, Choi SKY (2009) The processes of knowledge management in professional services firms in the construction industry: A critical assessment of both theory and practice. Journal of Knowledge Management 13(2):110-126, DOI: 10.1108/13673270910942736

Garnett N, Pickrell S (2000) Benchmarking for construction: Theory and practice. Construction Management and Economics 18(1):5563, DOI: 10.1080/014461900370951

Han SH, Kim DY, Jang HS, Choi S (2010) Strategies for contractors to sustain growth in the global construction market. Habitat International 34(1):1-10, DOI: 10.1016/j.habitatint.2009.04.003

Han SH, Kim DY, Kim H, Jang W-S (2008) A web-based integrated system for international project risk management. Automation in Construction 17(3):342-356, DOI: 10.1016/j.autcon.2007.05.012

Han SH, Park SH, Kim DY, Kim H, Kang YW (2007) Causes of bad profit in overseas construction projects. Journal of Construction Engineering and Management 133(12):932-943, DOI: 10.1061/ (ASCE)0733-9364(2007)133:12(932)

Hanna SA (2016) Benchmark performance metrics for integrated project delivery. Journal of Construction Engineering and Management 142(9):04016040, DOI: 10.1061/(ASCE)CO.1943-7862.0001151

Hastak M, Shaked A (2000) ICRAM-1: Model for international construction risk assessment. Journal of Management in Engineering 16(1):59-69, DOI: 10.1061/(ASCE)0742-597X(2000)16:1(59)

Hsueh SL, Perng YH, Yan MR, Lee JR (2007) On-line multi-criterion risk assessment model for construction joint ventures in China. Automation in Construction 16(5):607-619, DOI: 10.1016/ j.autcon.2007.01.001

Hwang BG, Zhao X, Chin EWY (2017) International construction joint ventures between Singapore and developing countries. Engineering, Construction and Architectural Management 24(2):209-228, DOI: 10.1108/ECAM-03-2015-0035

ICAK (2021) International construction information service. International Contractors Association of Korea (ICAK), Retrieved August 24, 2021, http://www.icak.or.kr (in Korean)

Iyer KC, Banerjee PS (2016) Measuring and benchmarking managerial efficiency of project execution schedule performance. International Journal of Project Management 34(2):219-236, DOI: 10.1016/ j.ijproman.2015.10.008

Jang Y, Kwon N, Ahn Y, Lee H, Park M (2019) International diversification and performance of construction companies: Moderating effect of regional, product, and industry diversifications. Journal of Management in Engineering 35(5):04019015, DOI: 10.1061/(ASCE)ME.19435479.0000713

Jepson J, Kirytopoulos K, London K (2020) Insights into the application of risk tools and techniques by construction project managers. International Journal of Construction Management 20(8):848-866, DOI: $10.1080 / 15623599.2018 .1494673$

Jha KN, Devaya MN (2008) Modelling the risks faced by Indian construction companies assessing international projects. Construction Management and Economics 26(4):337-348, DOI: 10.1080/ 01446190801953281

Jung W, Han SH (2017) Which risk management is most crucial for controlling project cost? Journal of Management in Engineering 33(5):04017029, DOI: 10.1061/(ASCE)ME.1943-5479.0000547

Jung W, Han SH, Park H, Kim DY (2010) Empirical assessment of internationalization strategies for small and medium construction companies. Journal of Construction Engineering and Management 136(12):1306-1316, DOI: 10.1061/(ASCE)CO.1943-7862.0000237

Kagioglou M, Cooper R, Aouad G (2001) Performance management in construction: A conceptual framework. Construction Management and Economics 19(1):85-95, DOI: 10.1080/01446190010003425 
Khan N (2017) Proposal of strategies for the implementation of the spanish construction companies in India. MSc Thesis, Polytechnic University of Valencia, Valencia, Spain

Kim HR, Kim DY, Jang HS (2019) Analyzing barrier factors due to overseas construction market environment changes: Focused on Korean construction companies. KSCE Journal of Civil Engineering 23(2):491-498, DOI: 10.1007/s12205-018-0933-6

Laryea S, Hughes W (2008) How contractors price risk in bids: Theory and practice. Construction Management and Economics 26(9):911924, DOI: 10.1080/01446190802317718

Lazzerini B, Mkrtchyan L (2011) Analyzing risk impact factors using extended fuzzy cognitive maps. IEEE Systems Journal 5(2):288297, DOI: 10.1109/JSYST.2011.2134730

Lee JK, Han SH, Jang W, Jung W (2018) "Win-win strategy" for sustainable relationship between general contractors and subcontractors in international construction projects. KSCE Journal of Civil Engineering 22(2):428-439, DOI: 10.1007/s12205-017-1613-7

Lee SH, Thomas SR, Tucker RL (2005) Web-based benchmarking system for the construction industry. Journal of Construction Engineering and Management 131(7):790-798, DOI: 10.1061/(ASCE)07339364(2005)131:7(790)

Li G, Zhang G, Chen C, Martek I (2020) Empirical bid or no bid decision process in international construction projects: Structural equation modeling framework. Journal of Construction Engineering and Management 146(6):04020050, DOI: 10.1061/(ASCE)CO.19437862.0001830

Ling FYY, Low SP, Wang SQ, Lim HH (2009) Key project management practices affecting singaporean firms' project performance in China. International Journal of Project Management 27(1):59-71, DOI: 10.1016/j.ijproman.2007.10.004

Liu R, Du J, Issa RRA, Giel B (2017) BIM cloud score: Building information model and modeling performance benchmarking. Journal of Construction Engineering and Management 143(4):04016109, DOI: 10.1061/(ASCE)CO.1943-7862.0001251

Liu J, Low SP, Zhang Q (2018) Enterprise risk management practices of top ENR international contractors. International Journal of Construction Management 18(5):364-374, DOI: 10.1080/15623599.2017.1326299

London K (2010) Multi-market industrial organizational economic models for the internationalization process by small and medium enterprise construction design service firms. Architectural Engineering and Design Management 6(2):132-152, DOI: 10.3763/aedm.2009.0111

Lu Y, Zhou L, Bruton G, Li W (2010) Capabilities as a mediator linking resources and the international performance of entrepreneurial firms in an emerging economy. Journal of International Business Studies 41(3):419-436, DOI: 10.1057/jibs.2009.73

Luu VT, Kim SY, Huynh TA (2008) Improving project management performance of large contractors using benchmarking approach. International Journal of Project Management 26(7):758-769, DOI: 10.1016/j.ijproman.2007.10.002

Lyons T, Skitmore M (2004) Project risk management in the Queensland engineering construction industry: A survey. International Journal of Project Management 22(1):51-61, DOI: 10.1016/s0263-7863(03) 00005-x

Ng ST, Tang Z (2008) Delineating the predominant criteria for subcontractor appraisal and their latent relationships. Construction Management and Economics 26(3):249-259, DOI: 10.1080/01446190701874405

Nguyen HT, Hadikusumo B (2017) Impacts of human resource development on engineering, procurement, and construction project success. Built Environment Project and Asset Management 7(1):7385, DOI: 10.1108/BEPAM-04-2016-0010
Nudurupati S, Arshad T, Turner T (2007) Performance measurement in the construction industry: An action case investigating manufacturing methodologies. Computers in Industry 58(7):667-676, DOI: 10.1016/ j.compind.2007.05.005

Ofori G (2007) Construction in developing countries. Construction Management and Economics 25(1):1-6, DOI: 10.1080/ 01446190601114134

Olawumi TO, Chan DWM (2019) Development of a benchmarking model for BIM implementation in developing countries. Benchmarking: An International Journal 26(4):1210-1232, DOI: 10.1108/BIJ-052018-0138

Oviedo-Haito JR, Jiménez J, Cardoso Francisco F, Pellicer E (2014) Survival factors for subcontractors in economic downturns. Journal of Construction Engineering and Management 140(3):04013056, DOI: 10.1061/(ASCE)CO.1943-7862.0000811

Packham G, Thomas B, Miller C (2003) Partnering in the house building sector: A subcontractor's view. International Journal of Project Management 21(5):327-332, DOI: 10.1016/S0263-7863(02)00046-7

Park H, Han SH, Rojas EM, Son J, Jung W (2011) Social network analysis of collaborative ventures for overseas construction projects. Journal of Construction Engineering and Management 137(5):344355, DOI: 10.1061/(ASCE)CO.1943-7862.0000301

Patel KV, Vyas CM (2011) Construction materials management in project sites. Proceedings of national conference on recent trends in engineering \& technology, May 13-14, Gujarat, India

Radujković M, Vukomanović M, Dunović IB (2010) Application of key performance indicators in South-Eastern European construction. Journal of Civil Engineering and Management 16(4):521-530, DOI: 10.3846/jcem.2010.58

Raz T, Michael E (2001) Use and benefits of tools for project risk management. International Journal of Project Management 19(1):917, DOI: 10.1016/S0263-7863(99)00036-8

Ribeiro LF, Fernandes TM (2010) Exploring agile methods in construction small and medium enterprises: A case study. Journal of Enterprise Information Management 23(2):161-180, DOI: 10.1108/ 17410391011019750

RICS (2020) Benchmarking in the infrastructure sector. Royal Institution of Chartered Surveyors (RICS), Retrieved October 13, 2021, https:// www.rics.org/en-in/news-insight/research/insights/benchmarking-inthe-infrastructure-sector/

Robinson HS, Anumba CJ, Carrillo PM, Al-Ghassani AM (2005) Business performance measurement practices in construction engineering organisations. Measuring Business Excellence 9(1):13-22, DOI: 10.1108/13683040510588800

Sexton M, Barrett P (2003) Appropriate innovation in small construction firms. Construction Management and Economics 21(6):623-633

Siraj NB, Fayek AR (2019) Risk identification and common risks in construction: Literature review and content analysis. Journal of Construction Engineering and Management 145(9):03119004, DOI: 10.1061/(ASCE)CO.1943-7862.0001685

Stewart R, Miller C, Mohamed S, Packham G (2003) Sustainable development of construction small and medium enterprises (SMEs): It impediments focus. Proceedings of CIB W78's 20th international conference on construction IT, construction IT bridging the distance, April 23-25, Waiheke Island, New Zealand

Sun WB, Jiang Y, He WZ (2012) Core competitiveness cultivation in small-medium construction enterprises. Applied Mechanics and Materials 174-177:3309-3312, DOI: 10.4028/www.scientific.net/ AMM.174-177.3309

Tabassi AA, Bakar AHA (2009) Training, motivation, and performance: 
The case of human resource management in construction projects in Mashhad, Iran. International Journal of Project Management 27(5):471-480, DOI: 10.1016/j.ijproman.2008.08.002

Takim R, Akintoye A (2002) Performance indicators for successful construction project performance. Proceedings of 18th annual ARCOM conference, September 2-4, Northumbria, UK

Tan Y, Xue B, Cheung YT (2017) Relationships between main contractors and subcontractors and their impacts on main contractor competitiveness: An empirical study in Hong Kong. Journal of Construction Engineering and Management 143(7):05017007, DOI: 10.1061/(ASCE)CO.1943-7862.0001311

Taroun A (2014) Towards a better modelling and assessment of construction risk: Insights from a literature review. International Journal of Project Management 32(1):101-115, DOI: 10.1016/ j.ijproman.2013.03.004

Thomas HR, Horman MJ, Souza UEL, Zavřski I (2002) Reducing variability to improve performance as a lean construction principle. Journal of Construction Engineering and Management 128(2):144154, DOI: 10.1061/(ASCE)0733-9364(2002)128:2(144)

Viswanathan SK, Jha KN (2020) Critical risk factors in international construction projects. Engineering, Construction and Architectural Management 27(5):1169-1190, DOI: 10.1108/ECAM-04-20190220

Westhead P, Wright M, Ucbasaran D (2001) The internationalization of new and small firms: A resource-based view. Journal of Business Venturing 16(4):333-358, DOI: 10.1016/S0883-9026(99)00063-4

Wood GD, Ellis RCT (2003) Risk management practices of leading UK cost consultants. Engineering, Construction and Architectural Management 10(4):254-262, DOI: 10.1108/09699980310489960

Xiao H, Proverbs D (2003) Factors influencing contractor performance: An international investigation. Engineering, Construction and Architectural Management 10(5):322-332, DOI: 10.1108/ 09699980310502937

Yeung JFY, Chan APC, Chan DWM, Chiang YH, Yang H (2013) Developing a benchmarking model for construction projects in Hong Kong. Journal of Construction Engineering and Management
139(6):705-716, DOI: 10.1061/(ASCE)CO.1943-7862.0000622

Yildiz AE, Dikmen I, Birgonul MT, Ercoskun K, Alten S (2014) A knowledge-based risk mapping tool for cost estimation of international construction projects. Automation in Construction 43:144-155, DOI: 10.1016/j.autcon.2014.03.010

Yiu DW, Lau C, Bruton GD (2007) International venturing by emerging economy firms: The effects of firm capabilities, home country networks, and corporate entrepreneurship. Journal of International Business Studies 38(4):519-540, DOI: 10.1057/palgrave.jibs.8400278

Yoo WS, Yang J, Kang S, Lee S (2017) Development of a computerized risk management system for international NPP EPC projects. KSCE Journal of Civil Engineering 21(1):11-26, DOI: 10.1007/s12205016-0784-y

Yu I, Kim K, Jung Y, Chin S (2007) Comparable performance measurement system for construction companies. Journal of Management in Engineering 23(3):131-139, DOI: 10.1061/(ASCE)0742-597X(2007) 23:3(131)

Yun S, Choi J, Oliveira DP, Mulva SP (2016) Development of performance metrics for phase-based capital project benchmarking. International Journal of Project Management 34(3):389-402, DOI: 10.1016/j.ijproman.2015.12.004

Yun S, Jung W (2017) Benchmarking sustainability practices use throughout industrial construction project delivery. Sustainability 9(6):1007, DOI: 10.3390/su9061007

Zayed T, Amer M, Pan J (2008) Assessing risk and uncertainty inherent in Chinese highway projects using AHP. International Journal of Project Management 26(4):408-419, DOI: 10.1016/j.ijproman.2007.05.012

Zhao X, Hwang BG, Yu GS (2013) Identifying the critical risks in underground rail international construction joint ventures: Case study of Singapore. International Journal of Project Management 31(4):554-566, DOI: 10.1016/j.ijproman.2012.10.014

Zhu F, Hu H, Xu F, Tang N (2021) Predicting the impact of countryrelated risks on cost overrun for overseas infrastructure projects. Journal of Construction Engineering and Management 147(2): 04020166, DOI: 10.1061/(ASCE)CO.1943-7862.0001959 